\title{
Sleep Management: A Frontier for Improved Academic Performance
}

\author{
James M. Gregory \\ College of Engineering \\ Texas Tech University \\ Xuepeng Xie \\ Computer Science Department \\ Texas Tech University \\ Susan Mengel \\ Computer Science Department \\ Texas Tech University
}

\begin{abstract}
Student safety, both in driving and academic performance, depends on successful sleep management. Usually driving and learning through lectures and reading are passive or low stimulation activities. Therefore, they are highly sensitive to the accumulation of sleep debt. In November 2002 on Channel 11 News in Lubbock, Texas, it was reported that driving with 18 hours of sleep debt was equal to driving with 0.05 percent blood alcohol.

The authors of this paper have developed a web-based interactive human performance sleep simulation model that considers inputs of sleep, alcohol, and caffeine to predict both active and passive performance efficiencies. A direct application can be made to predict active and passive learning. This simulation tool predicted a drop of about 55 percent in passive performance efficiency for both 0.05 percent blood alcohol and 18 hours of sleep debt. The simulation gives an 80 percent drop in efficiency for the combination of 0.05 percent blood alcohol and 18 hours of sleep debt. This paper will include information about the development and use of this model to improve student academic performance.
\end{abstract}

\section{Introduction}

Sleep is required for human life; it is just as essential as air, water, and food. Humans become highly stressed and eventually die when they are denied air, water, food and sleep. For air, problems develop in a matter of minutes depending on metabolism and health of the individual. With water, problems develop within a few days. With sleep, problems develop within a few weeks. ${ }^{1}$ For food, problems and death occur in a matter of a few months depending on the initial weight of the individual. Mental alertness and 
performance is severely reduced before the limits of death are reached. This paper will focus on sleep.

Many people of all ages under estimate the value of sleep and do not practice proper sleep management. College students are no exception. They often place their academic performance and even their life at risk with poor sleep management. During 2002, at least five students at Texas Tech University died in automotive crashes as a result of a sleepy driver. Most were associated with travel during spring break. During the same time frame, five other college students from Abilene Christian University died in a single-car accident when the driver fell asleep and crashed into a bridge. It is common knowledge that drowsy driving is a major cause of highway accidents - almost as serious as drinking and driving. ${ }^{2}$ A need, thus, exists to help people understand the factors that affect sleep management and to predict the consequences or risks associated with an individual's sleep management.

The objective of this paper is to overview the development of a sleep simulation model that is currently available from a website known as E-COACH, Electronic College Optimal Advisor and Career Helper. As an electronic coach, E-COACH provides several tools to help students, teachers, advisors, counselors, and professionals to better understand the education process and how to adjust life management to improve academic and other performances. This paper will present both short- and long-term sleep debt scenarios and the associated predicted active and passive performances. Sleepy students are obviously at high risk of poor learning in passive learning environments. We will also compare predicted outcomes with outcomes that have been reported in the literature or media.

\section{SLEEP (Sleep Loss Effects on Everyday Performance) Model}

It is widely recognized that sleep loss reduces human performance. While the effect is well known, we have not found evidence of anyone modeling the sleep process and the sleep loss effect on academic performance until the development of GREG (Grade Requirements Evaluation Game) in 1997. 3,4,5,6 GREG simulates the learning/teaching process and predicts GPA (grade point average) for students in college. GREG includes a sleep model that predicts alertness (efficiency for passive learning) and test-taking efficiency (active learning). These two efficiencies are used to predict the final outcome, college GPA. The learning efficiency in the GREG program is a product of several other efficiencies, one of which is the passive alertness that varies with sleep management.

GREG even includes a caffeine adjustment for passive learning. GREG does not include the effects of caffeine or alcohol in the blood to suppress the onset of REM (rapid eye movement) sleep. REM sleep is associated with mental renewing and mental performance. When the sleep subroutine in GREG was developed, it was discovered that the simulation had to extend for at least five weeks to reach steady-state conditions. The sleep literature confirmed that four to six weeks are necessary to reach steady-state conditions. ${ }^{7}$

Proceedings of the 2003 ASEE Gulf-Southwest Annual Conference

The University of Texas at Arlington

Copyright (C 2003, American Society for Engineering Education 
The sleep model in GREG became the foundation for a more complete dynamic sleep model that can predict the effects of daily sleep length for up to five weeks in sequence. Several new components were developed and added to the sleep model including alcohol and caffeine functions to predict concentrations in the blood as a function of consumption, bodyweight, and time to metabolize the chemicals (alcohol and/or caffeine). The REM fraction equation in GREG was redeveloped to adjust REM fraction as a function of REM latency, which varies as a function of amount and type of chemical(s) in the body at bedtime. A function to predict the average time needed to fall asleep was also added as a third dependent variable. While there are several internal dependent variables that are then used to predict something else, the general sleep model has four dependent variables: active or stimulated efficiency, passive or un-stimulated efficiency, time to fall asleep, and sleep debt. An equation was also developed to shift the circadian cycle as a function of bedtime and sleep length. This addition allows the sleep model to adjust for jetlag or shift work. The calibration for jetlag changes depending on east or west travel.

While the sleep model is complex and fairly complete, it does not include the effects of food consumption (amount and timing) on metabolism. It does not include the effect of age on sleep interruptions during the sleep period. It does not include functions to simulate sleep disorders. It does not include learning disabilities or other inputs that may cause a shift in brainwave patterns or relative amounts of alpha, delta, or theta waves. It is however, functional for all ages. The research version of the sleep model will even accept a negative age input to adjust REM sleep fraction and sleep need for premature births. On the other end of the age spectrum, the database ${ }^{8}$ used for calibration of the sleep need function included ages up to about 80 years. The mathematical function at the upper end of the age spectrum is very stable and nearly flat; thus, we are comfortable with the sleep need function for all ages. The sleep need function is for healthy people and does not include the effects of disease, depression, anxiety, etc. on sleep need. We also do not adjust sleep need prediction for metabolism differences between people although we have an equation developed to consider this effect. We also do not consider elevation differences on sleep need or predict rhythmic breathing during sleep for people at high elevations. Thus, our sleep model will miscalculate sleep need and mental performance at high elevations. To be safe, or model should be used for elevations less than 10,000 or 11,000 feet. It will certainly miscalculate for elevations of 15,000 feet and higher.

The sleep research model was reprogrammed with web-based graphic tables to conveniently input data. A menu was also developed to allow the user to select the type of output desired: table or graph. This menu is shown in the output figures later in this paper. The sleep research model was initially programmed in BASIC. Because of this initial start, we have continued to use BASIC for development, although the limitation of memory has become a problem for long simulation periods. The BASIC model was reprogrammed using Active Server Pages to function in a web environment. Because Active Server Pages does not support the use of subroutines, extensive effort was needed to work around this limitation. The final result is SLEEP Model, which is now available as part of E-COACH.

\author{
Proceedings of the 2003 ASEE Gulf-Southwest Annual Conference \\ The University of Texas at Arlington \\ Copyright (C) 2003, American Society for Engineering Education
}


Users can access SLEEP Model by going to the College of Engineering web page, www.coe.ttu.edu. Click on E-COACH. At E-COACH, select ED DOCTOR. ED DOCTOR provides access to GREG (learning how to learn button), SLEEP Model (Professional Work), and other tools that help students and professionals with education or career development.

\section{Results}

SLEEP Model can be used to generate simulated results in about 10 minutes or less. The first result to be presented is a comparison of passive performance (driving) with 0.05 percent blood alcohol to performance with 18 hours of sleep debt.

Before we proceed with the comparison, note that the performance associated with blood alcohol percentage was calibrated for graduate-student performance playing the game Mine Sweeper. Success at playing Mine Sweeper is a mental function. Two measures of performance were used with the Mine Sweeper data: (1) how many mistakes occurred before achieving three successful games and (2) how long did the individual have to play the game before achieving three successful games. Efficiencies were developed for each measure associated with the consumption of one beer every 30 minutes. Both efficiencies were similar and were averaged to produce a very smooth continuous function to predict performance associated with alcohol consumption.

In November 2002 on Channel 11 News in Lubbock, Texas, it was reported that driving with 18 hours of sleep debt was equal to driving with 0.05 percent blood alcohol. We decided to simulate these conditions with SLEEP Model. We adjusted the number of beers and the duration of drinking starting with a 11:00 lunch time period until we achieved or slightly exceeded 0.05 percent blood alcohol in the simulation. We used four beers in 2.5 hours of drinking time. The result is shown in Figure 1 as the first downward spike. Both active and passive efficiencies dropped the same amount. We simulated a night without sleep occurring later in the week. We used a bedtime of 11:30 pm for normal sleep including the day before the night without sleep. The blue line in Figure 1 shows the drop in passive performance. After 18 hours from the wakeup time ( 8 hours after bedtime), the passive efficiency was essentially the same as the performance with 0.05 percent blood alcohol. The passive performance continued to decline during the early morning hours then after about 4 am started to increase. The passive performance increased the following day but was reduced more than 25 percent from the previous day. This drop of over 25 percent represents at least a two-letter grade drop in academic performance during passive lectures. Because the sleep debt last longer than the blood alcohol level, the drowsy driver is actually a worse threat than the drinking driver. 


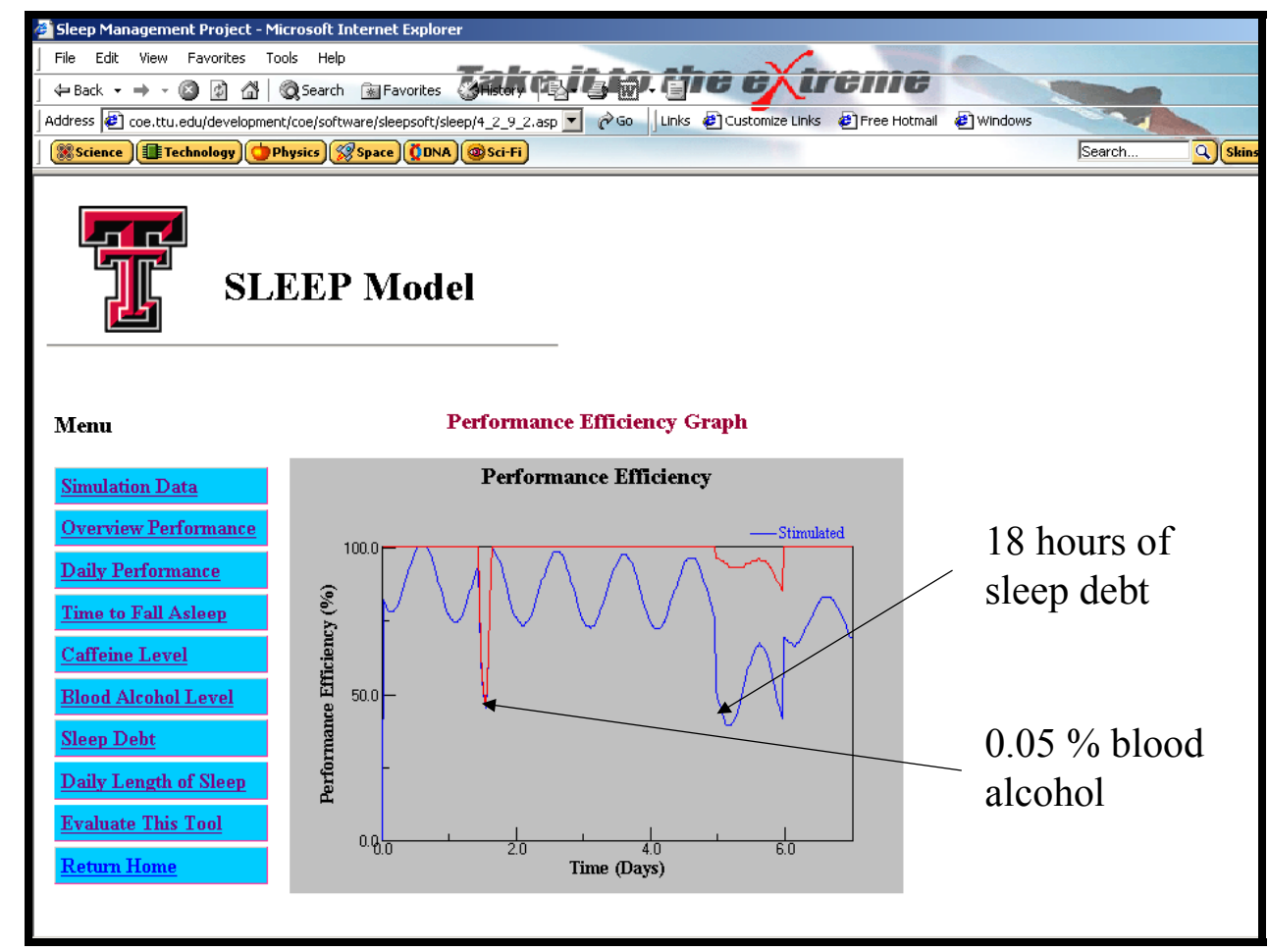

Figure 1. Comparison of performance with 0.05 blood alcohol and passive performance after 18 hours of sleep debt.

Many people use caffeine to help stay awake. Caffeine has the potential to move the performance efficiency up toward the red line (active efficiency). The use of radio, books on tape or $\mathrm{CD}$, etc. also creates natural stimulation to move the individual up to or at least toward the active performance curve. Thus, with stimulation, the driver with sleep debt is dangerous but not as dangerous as the drinking driver.

Our second application is for a long-term gradual build up of sleep debt. Stanly Coren reported in his book ${ }^{1}$ about an experiment he conducted on himself. He started out needing and getting eight hours of sleep per day. He gradually reduced sleep amount. Generally, he dropped 30 minutes per day as he started a new week. The objective was to gradually condition the body to need less sleep. The real result was a gradual build up of sleep debt and reduced performance at work. For this paper, we will focus on the time to fall asleep. The 45-day period was longer than the five weeks that SLEEP Model considers. We simulated the first 35 days, and then we used the sleep debt amount to start the last 10 days of simulation. The time to fall asleep for the first 35 days is shown in Figure 2. Figure 3 shows the last 10 days. Dr. Coren reported that he fell asleep at two different stoplights on the way home from work on the last day. Our simulation indicated he had only 18 to 24 seconds (depending on the age we use) before falling asleep with no stimulation. The predicted time to fall asleep is easily within the cycle time for most four-way stoplights with left-turn signal. Our Civil Engineering transportation people indicate that some stoplights can take as long as 90 seconds to complete one cycle. All stoplights take at least 20 seconds to cycle. In other words, our simulation results are close to observations reported by Dr. Coren. 


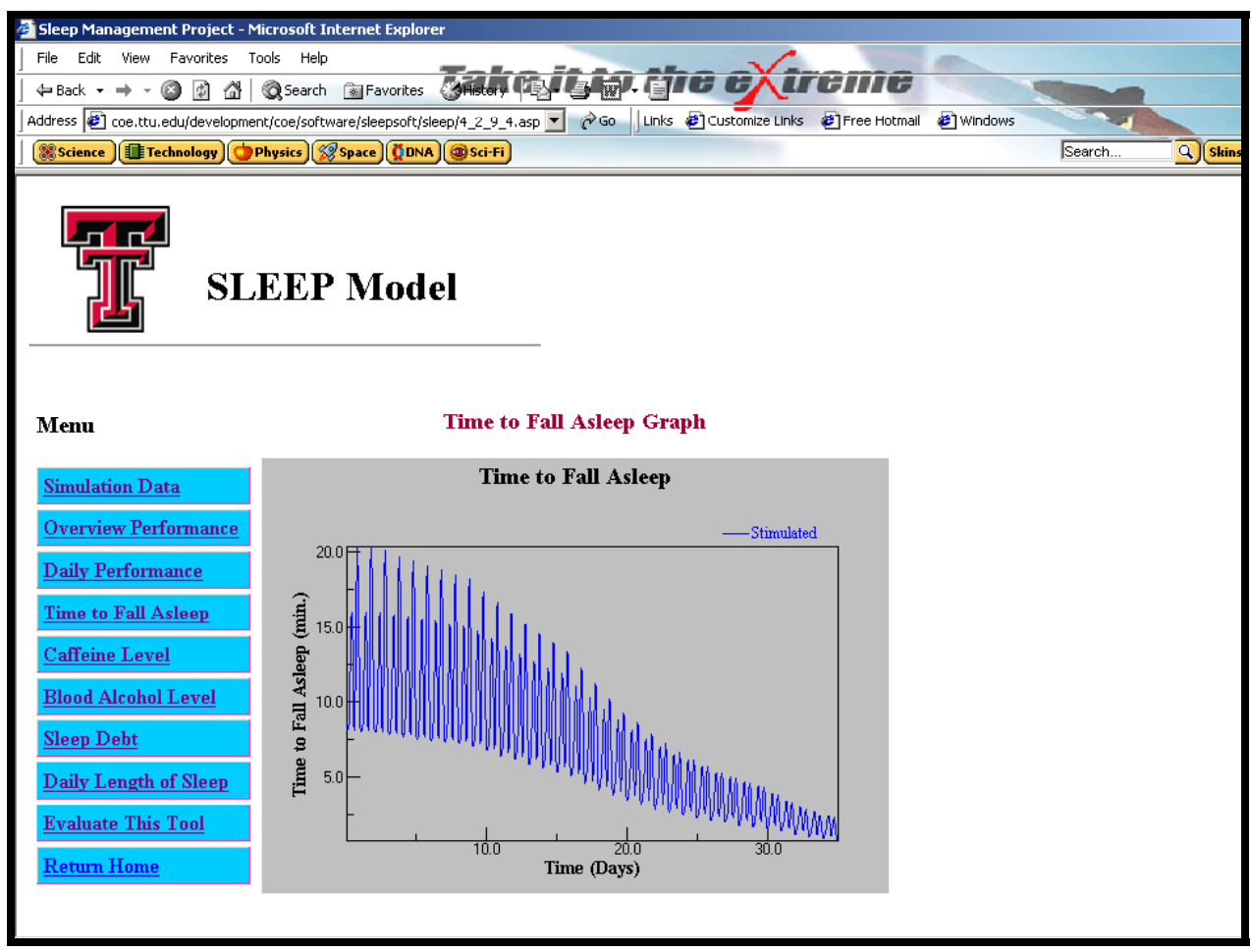

Figure 2. Decline in time to fall asleep over a 35-day period of building up sleep debt.

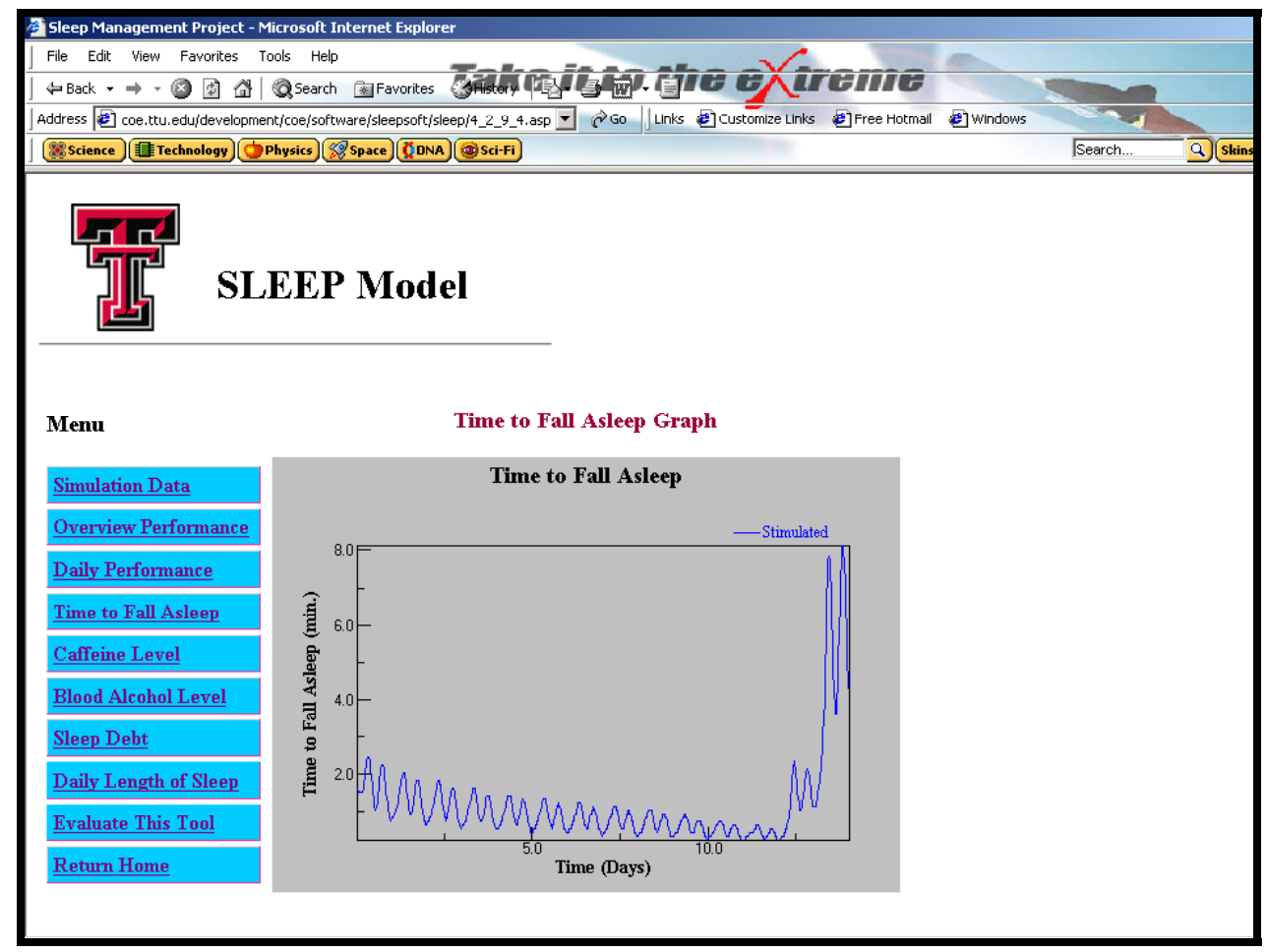

Figure 3. Decline for the last 10-day period of increasing sleep debt and recovery of time to fall asleep associated with unrestricted sleep for the last three days.

Proceedings of the 2003 ASEE Gulf-Southwest Annual Conference

The University of Texas at Arlington

Copyright (C) 2003, American Society for Engineering Education 
It is interesting how quickly we can recover an increased time to fall asleep if we allow our body to have unlimited sleep. In Figure 3, recovery is shown for the last three days. He reported that he slept for about 12 hours. We predicted values close to this amount. Thus, even if we have serious sleep debt, a good night sleep can help us have enough time to be stimulated before falling asleep.

Figures 2 and 3 also have another implication about teaching. Teachers, even for ideal conditions, will cause their students to fall asleep in class with passive teaching longer than 20 minutes without stimulation. The 20-minute attention span that is sometime associated with learning may really be a sleep function. Obviously, active learning associated with active teaching avoids this risk.

\section{Sleep and Academic Success}

Certainly not all students have sleep problems - many, however do! We have had students come back to us after counseling and making changes on their sleep management and tell us "sleep works." We have also experienced one or two students who bought a new computer game and played it day and night through the weekend then crashed the following week failing to attend class. Addictive behavior was probably the primary problem, but the mismanagement of sleep caused the immediate failure during that semester.

We use both the GREG program and the SLEEP Model to help students to analyze interference to academic performance. Both programs calculate a number defining the severity of the problem associated with a given management choice. GREG allows students to see the long-term chronic impact of sleep management. SLEEP Model helps students to see the dynamic nature of sleep management, such as driving safety and the effects of going without sleep on the ability to be alert and receive information during lectures.

From our experience in working with students with learning disabilities, it appears that lack of sleep appears to make a learning disability express itself with more severity. Stanley Coren ${ }^{1}$ even reported from his experiment that the build up of sleep debt caused him to develop dyslexic traits that he did not have when he received adequate sleep.

We have even discovered that some of our students tend to drink alcohol. Associate deans see a variety of problems. We have learned to use the sleep information and sometimes the SLEEP Model to inform students that six beers at bedtime results in onethird less REM sleep. Twelve beers reduce REM sleep by two-thirds. It is relatively easy to then discuss how alcohol consumption can lead to sleep debt and the loss in desire to attend class the following Monday morning.

We have learned over the years in working with students that people in general do not like being told what to do or that they need to change behavior. Web-based education tools, such as GREG and SLEEP Model allow people to discover how management affects outcomes. Students discover the problem or problems that are interfering with

Proceedings of the 2003 ASEE Gulf-Southwest Annual Conference

The University of Texas at Arlington

Copyright (C) 2003, American Society for Engineering Education 
their academic success. They can then decide to make changes of their choice to solve the problem. They, thus, develop ownership in their new academic plan. Not all students choose to improve.

\section{Future Work}

While SLEEP Model is functional and has matched a couple of outcomes reported in the literature and media, it is a work in progress. We plan to redevelop the graphics output component to make the lettering larger and the scales more meaningful. We also plan to reprogram other areas of the model. For example, during sleep recovery, there is a spike up in the two efficiency curves at the initial time of sleep associated with renewal. The current model causes a step function when it should distribute the increase over the sleep period. Because people are sleeping and not really performing during the sleep period, the current miscalculation has little real impact on the model use. It does cause the graphs to look bad.

We also hope to add a food function to account for sleepy drivers and students after large carbohydrate meals. We have a start on an equation to make this prediction, but we do not have it fully calibrated and tested at this time.

\section{Summary and Conclusions}

A web-based sleep simulation model to predict active and passive performance associated with sleep has been developed and presented. We have found that this information is very useful in helping students discover solutions to academic problems. The model also helps explain why students tend to fall asleep in some classes and not in others: active or passive learning environments.

Sleep management is a very serious issue for students. Young people die from auto accidents related to drowsy drivers. People also perform poorly on academic work when they have sleep debt. We strongly urge students and teachers to become familiar with the effects of sleep management on daily performance and to implement changes to improve sleep management. We also urge teachers to use active teaching to stimulate students and reduce the effects of sleep debt on academic performance.

\section{References}

1. Coren, S., 1996, Sleep Thieves: An eye-Opening Exploration Into the Science \& Mysteries of Sleep, The Free Press, New York.

2. 2001 "Sleep in America" Poll, National Sleep Foundation, Washington, DC.

3. Gregory, J. M., Heinze, L. R., Bagert, D. J., Mengel, S. A., 2002, E-COACH: A Paradigm Shift for Efficient Advising, Frontiers in Education, Boston, Massachusetts.

4. Gregory, J. M., 1992, A Learning Simulation Model. ASAE Paper No. 927030 presented at the Summer ASAE Meeting, Charlotte, North Carolina.

Proceedings of the 2003 ASEE Gulf-Southwest Annual Conference

The University of Texas at Arlington

Copyright (C) 2003, American Society for Engineering Education 
5. Gregory, J. M., 1993, GREG: A Computer Program to Learn How to Learn, Paper written for the annual meeting of American Society for Engineering Education (Gulf-Southwest Section), Austin, Texas.

6. Gregory, J. M., Carter, W. J., Gregory, P. S., 1997, The Student's Handbook for Academic Survival in College, McGraw-Hill.

7. Maas, J. B., Wherry, M. L., Axelrod, D. J., Hogan, B. R., Blumin, J. A., 1999, Power Sleep: The Revolutionary Program that Prepares Your Mind for Peak Performance, HarperPerennial, New York.

8. Roffward, H. P., Muzio, J. N., Dement, W. C., 1966, Ontogenetic Development of the Human Sleep-Dream Cycle, Science 152:604-619.

\section{JAMES M. GREGORY}

Dr. Gregory has served as Associate Dean for Undergraduate Studies in the College of Engineering at Texas Tech University for eight years. He has spent over a decade in the research and development of tools to improve engineering education and student success in college. Dr. Gregory is a registered Professional Engineer in Texas.

\section{XUEPENG XIE}

Mr Xie is currently a graduate student in the Department of Computer Science at Texas Tech University. He has obtained a M.Sc. in Chemistry from Zhejiang University, P.R.China and a M.E. in Materials Engineering from Nanyang Technological University, Singapore.

\section{SUSAN MENGEL}

Dr. Mengel is an Associate Professor in Computer Science at Texas Tech University. She is active in software engineering education research having developed a software process for students to use in the undergraduate and graduate software engineering courses. She is active professionally serving on the IEEE Computer Society Board of Governors, Conferences and Tutorials Board, Web Redesign Committee, and Educational Activities Board. 